\title{
Endogenous opioid actions and effects of environmental disturbance on parturition and oxytocin secretion in rats
}

\author{
G. Leng, S. Mansfield, R. J. Bicknell, R. E. Blackburn, D. Brown, \\ C. Chapman, R. G. Dyer, S. Hollingsworth, K. Shibuki*, J. O. Yates \\ and S. Way \\ A.F.R.C. Institute of Animal Physiology and Genetics Research, Babraham, Cambridge CB2 4AT, \\ U.K.
}

\begin{abstract}
Summary. Blood samples were taken from conscious, chronically-catheterized rats during parturition for measurement of oxytocin by specific radioimmunoassay. After the birth of the $3 \mathrm{rd}$ pup, rats were allowed to remain in their nesting cage (undisturbed rats) or were transferred for $45 \mathrm{~min}$ to a glass bowl (disturbed rats); at the time of transfer, rats were given an i.v. injection of the opioid antagonist naloxone or saline vehicle. Subsequent parturition was prolonged in saline-treated disturbed rats, but not in naloxone-treated disturbed rats. Parturition was significantly hastened in naloxonetreated undisturbed rats. Naloxone injections were followed by a large rise in plasma oxytocin concentrations in disturbed and undisturbed rats. We conclude, from a statistical analysis of the relationship within experimental groups between plasma oxytocin concentration and speed of parturition, that the effects of disturbance and of naloxone upon parturition may be accounted for, at least in part, by their effects upon oxytocin release. However, the effects of disturbance on parturition may not be mediated entirely by activation of opioid pathways. Naloxone did not potentiate oxytocin release in nonpregnant rats, or on Day 1 post partum, but did potentiate oxytocin release on Day 22 of pregnancy even in rats before the onset of parturition. Endogenous opioid pathways regulating oxytocin release therefore appear to be active during late pregnancy and during parturition itself.
\end{abstract}

Keywords: opioids; oxytocin; parturition; naloxone; environmental disturbance; rat

\section{Introduction}

A pregnant rat will normally give birth to between 6 and 14 young over a period of $1-2 \mathrm{~h}$ on the afternoon of Day 22 or 23 of pregnancy. The progress of parturition in the rat depends upon the release of oxytocin from the maternal neurohypophysis (Higuchi et al., 1985, 1986, 1987). If morphine is administered centrally or peripherally following the birth of the 3rd pup, plasma oxytocin concentrations are reduced, and the duration of parturition is greatly prolonged (Gosden et al., 1985; Cutting et al., 1986). We have shown previously that parturition is also disrupted in rats transferred to a novel environment following the birth of the 3rd pup, and that this disruption can be prevented by i.v. administration of the opiate receptor antagonist naloxone (Leng et al., 1985). We suggested that environmental disturbance leads, in the parturient rat, to activation of endogenous opioid pathways inhibitory to the secretion of oxytocin (see Dyer, 1988).

\footnotetext{
*Present address: Department of Physiology, Jichi Medical School, Minamikawachi-Machi Kawachi-Gun, Tochigi-
} Ken, Japan 329-04. 
However, naloxone elevates oxytocin secretion during parturition in undisturbed rats as well as in disturbed rats, and on Day 22 of pregnancy even before the onset of parturition (Hartman et al., 1986). Opioid pathways may therefore be actively regulating oxytocin secretion in the absence of any imposed external stress, as suggested also by an earlier study on parturition in rats implanted chronically with subcutaneous minipumps to release either naloxone or saline (Leng et al., 1985).

In the present study we tested the hypothesis that the effects of naloxone and of environmental disturbance are associated with changes in plasma oxytocin concentration, and examined statistical models of interaction between the effects of disturbance and those of naloxone on parturition and on oxytocin release.

\section{Materials and Methods}

Animals. Virgin Wistar rats of 200-250 g body weight were housed overnight in groups of 4-7 with a sexually experienced male. The following morning, vaginal smears were taken and inspected for the presence of spermatozoa. The day of detection of spermatozoa was taken as Day 1 of pregnancy. Pregnancy was confirmed on Day 16 by palpation, and pregnant rats were thereafter caged singly in their 'nesting cages'. Rats that failed to become pregnant were used as non-pregnant controls for oxytocin measurements. All rats were maintained throughout on a $14 \mathrm{~h} \mathrm{light:10 \textrm {h } \text { dark }}$ schedule (lights on at 05:00 h). On the morning of Day 22 (or on the morning of the experiment for animals sampled at other times), rats were anaesthetized with ether for implantation of a jugular catheter. The catheter was exteriorized through an incision at the back of the neck, and for its length outside the animal was enclosed in a light, wound steel sleeve.

After recovery from the anaesthetic, rats were watched continuously until parturition began: red light illumination was used for observations during the dark phase of the light:dark cycle. The times of birth of each pup were noted. Up to 8 blood samples, each of $0.25-0.30 \mathrm{ml}$ replaced immediately with an equal volume of heparinized saline $(0.9 \%(\mathrm{w} / \mathrm{v})$ $\mathrm{NaCl}$ ), were taken from each rat for measurement of oxytocin by radioimmunoassay. Sampling was initiated following the birth of the 2nd and/or 3rd pups. After the birth of the 3rd pup, rats were given an i.v. injection of naloxone hydrochloride ( $2 \mathrm{mg} / \mathrm{kg}$; Sigma, St Louis, MO, U.S.A.; $1 \mathrm{mg} / \mathrm{ml}$ solution in $0.9 \% \mathrm{NaCl}$ ) or of an equivalent volume of $0.9 \% \mathrm{NaCl}$ alone. Thereafter, rats were allowed to remain in the nesting cage (undisturbed rats) or were transferred to an empty glass bowl, where they remained for $45 \mathrm{~min}$ (disturbed rats) or for $15 \mathrm{~min}$, when they were returned to the nesting cage for $15 \mathrm{~min}$ and then again to the glass bowl for $15 \mathrm{~min}$ (repeatedly disturbed rats). Repeatedly disturbed rats given naloxone at the time of the first transfer were given supplementary naloxone injections of $0.5 \mathrm{mg} / \mathrm{kg}$ at the time of the second and third transfers.

Further blood samples were taken at various times during the $45 \mathrm{~min}$ after the birth of Pup 3. Some rats were killed at this time, and dissected to inspect the remaining contents of the uterus. In these rats, the neurointermediate lobe of the pituitary was dissected out onto solid $\mathrm{CO}_{2}$ and stored at $-70^{\circ} \mathrm{C}$ until assayed for total oxytocin content.

Measurement of oxytocin. Blood samples were immediately stored on ice. Plasma was separated by centrifugation, and stored at $-20^{\circ} \mathrm{C}$. Neurointermediate lobes were homogenized in $0.1 \mathrm{M}-\mathrm{HCl}$. Oxytocin was measured by radioimmunoassay using the method and antiserum of Higuchi et al. (1985), in duplicate aliquants of each sample. Interassay and intra-assay coefficients of variation were $14.4 \%$ and $13.1 \%$ respectively (data pooled from 9 assays; the standard used for the coefficients was $260 \mathrm{pg} / \mathrm{ml}(13 \mathrm{pg} /$ tube $) ; 7$ standards in each assay). The sensitivity of the assay varied between 2 and $4 \mathrm{pg} / \mathrm{ml}(0 \cdot 1-0 \cdot 2 \mathrm{pg} /$ tube $)$ determined from twice the s.d. about the zero binding points.

Statistical analysis of data. Comparisons of inter-birth intervals and oxytocin concentrations between the differently treated groups of animals was made by Mann-Whitney $U$ tests. The relationship between the increment in oxytocin concentrations between the birth of Pup 3 and $8-15$ min later, and the experimental treatment, was determined by maximum likelihood fit of a nonlinear model. The model assumed that the change in plasma oxytocin concentration is normally distributed with expectations specified in terms of inter-birth interval by the formulae in Table 2. The mean $\log$ oxytocin value between 8 and 15 min after the birth of Pup 3 was obtained by weighted and unweighted least squares, the differential weighting reflecting the greater variability of the naloxone treated group. All analyses were carried out using the Genstat 5 statistical programming language (Genstat 5 Reference Manual, Genstat 5 Committee, Clarendon Press, Oxford 1987) on a VAX 750 computer.

\section{Results}

\section{Duration of parturition in undisturbed rats}

The time course of parturition was similar in the uncannulated control rats, the rats cannulated but not sampled, and the blood-sampled rats: the mean interval between the birth of Pups 3 and 6 
was $25.2 \pm 3.8 \mathrm{~min}(n=9), 28 \pm 6.0 \mathrm{~min}(n=4)$ and $24.9 \pm 3.2 \mathrm{~min}(n=14)$ in the three groups respectively. We therefore combined data from uncannulated and cannulated rats in the subsequent analysis.

In 30 control (undisturbed, saline-injected) rats at least 6 pups were either born or remained in utero at the end of the experiment. Pregnancies resulting in fewer than 6 pups were invariably the result of unilateral implantations: the time course of parturition was slower and more variable in such rats, and all data from rats with fewer than 6 pups were therefore excluded. Of the 30 control rats, 29 had at least 8 pups. In 19 of these 29 rats the 8 th pup was born within 45 min of the $3 \mathrm{rd}$, and in 6 within $30 \mathrm{~min}$ of the $3 \mathrm{rd}$. The full time course of parturition in the control rats is shown in Fig. 1.

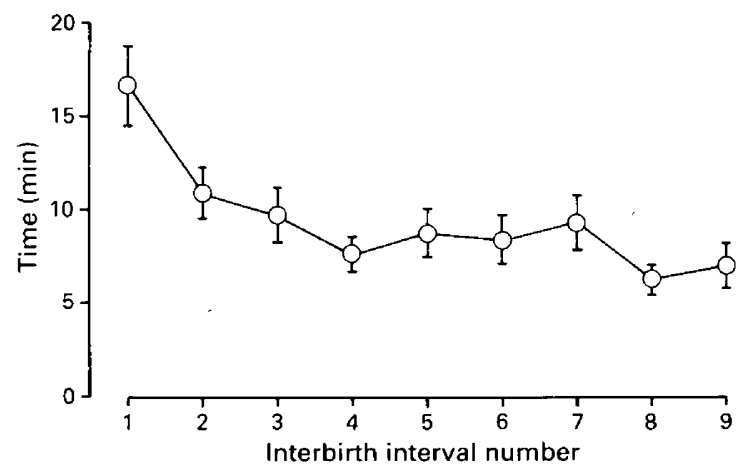

Fig. 1. Mean intervals ( \pm s.e.) between births for the first 8 pups born to 29 undisturbed rats.

\section{Effects of disturbance on established parturition}

In disturbed rats there was again no difference in the pattern of parturition between cannulated and uncannulated rats and data have been combined. In this group 23 rats had at least 6 pups, and all but one of these at least 8 pups. The 8 th pup was born within 45 min of the 3 rd in only 5 of these 22 rats, and within $30 \mathrm{~min}$ in none of the rats. The disturbance following the birth of the Pup 3 therefore resulted in a prolongation of parturition, and this effect was seen most markedly as a prolongation of the interval between the birth of Pups 3 and 4 (Fig. 2). In control rats, this interval was $9.7 \pm 1.3 \mathrm{~min}(n=30)$ compared with $19.6 \pm 2.3 \mathrm{~min}(n=23)$ in disturbed rats, whereas the intervals between the births of subsequent pups were similar in the two groups. The difference in the cumulative interval between Pups 3 and $6(25.4 \pm 2.0 \mathrm{~min}$ in control rats; $36.5 \pm 2.0 \mathrm{~min}$ in disturbed rats) is therefore almost wholly attributable to the prolonged interval between the birth of Pups 3 and 4.

In repeatedly disturbed rats, the effects of the disturbance on parturition were less easy to analyse. The interval between the birth of Pups 3 and $4(18.8 \pm 2.3 \mathrm{~min} ; n=18)$ was similar to that in the rats disturbed only once-not surprisingly since for the first $15 \mathrm{~min}$ after the birth of Pup 3 these two groups were treated identically. To examine the effect of the subsequent return to the nesting cage, and then $15 \mathrm{~min}$ later of a second transfer to the glass bowl, we compared the distribution of births in these three 15-min intervals for Pups 3 to 8 (for rats with at least 8 pups). Of the 18 repeatedly disturbed rats, 3 gave birth to Pup 8 within 30 min of Pup 3, but only 6 of the remaining 15 rats gave birth to any pups in the $15 \mathrm{~min}$ following return to the glass bowl (Table 1 ). By contrast, in the corresponding time interval (31-45 min after the birth of Pup 3) 21 out of the 23 disturbed rats gave birth to 1 or more pups. It therefore appeared that the disruption of parturition was effected mainly by the environment of the glass bowl itself rather than by the act of physically 


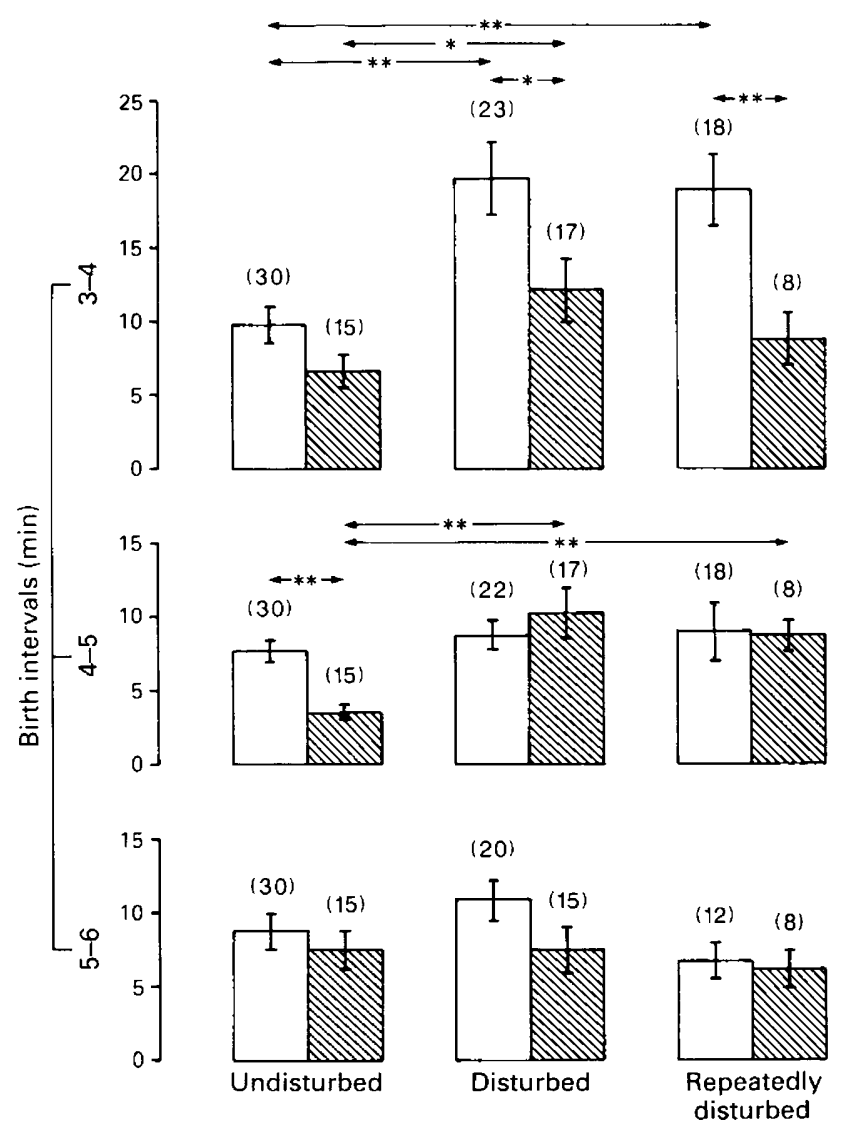

Fig. 2. Effects of disturbance and of naloxone hydrochloride injection (i.v.; $2 \mathrm{mg} / \mathrm{kg}$ body wt) on the progress of parturition in rats. Means ( \pm s.e.) of inter-birth intervals for the birth of Pups 4, 5 and 6. Hatched bars are data from naloxone-treated rats; open bars are from salinetreated rats. The number of intervals contributing to each bar is given in parentheses above each bar. ${ }^{*} P<0.05 ;{ }^{* *} P<0.01$ (Mann-Whitney $U$ test).

disturbing the rat by moving it from one place to another since in the repeatedly transferred rats, transfer from cage to bowl resulted in a disruption of parturition whereas the reverse transfer did not. Moreover, the data indicate that rats remaining in the bowl for $45 \mathrm{~min}$ had, after $30 \mathrm{~min}$, become tolerant to the disruptive effects of this environment upon parturition since, comparing parturition in the period 30-45 min after the birth of Pup 3, fewer of the repeatedly disturbed rats gave birth than did the disturbed rats.

\section{Effects of naloxone on parturition}

The time course of parturition in the disturbed rats given naloxone was significantly faster than in disturbed rats given saline, and was similar to that in undisturbed control rats (Fig. 2). In repeatedly disturbed rats also, naloxone treatment reversed the disruption of parturition completely. However, undisturbed, naloxone-treated rats gave birth significantly more quickly than did disturbed, naloxone-treated rats or undisturbed control rats (Fig. 2). In 15 undisturbed, naloxonetreated rats the mean interval between the birth of Pups 3 and 6 was $17.6 \pm 1.6$ min compared with $25.4 \pm 2.0 \mathrm{~min}$ in 30 undisturbed, saline-treated rats $(P<0.01)$. 
Table 1. Numbers of rats giving birth (Pups 4-8 only) per 15-min period following transfer from their nesting cage to a glass bowl after the birth of Pup 3

\begin{tabular}{|c|c|c|c|}
\hline & \multicolumn{3}{|c|}{ Time after birth of Pup 3} \\
\hline & $0-15 \mathrm{~min}$ & $16-30 \mathrm{~min}$ & $31-45 \min \dagger$ \\
\hline & Birth:no birth & Birth:no birth & Birth:no birth \\
\hline $\begin{array}{l}\text { Disturbed } \\
\text { rats* }\end{array}$ & $\begin{array}{c}10: 13 \\
\text { (bowl) }\end{array}$ & $\begin{array}{l}20: 3 \\
\text { (bowl) }\end{array}$ & $\begin{array}{l}21: 2 \\
\text { (bowl) }\end{array}$ \\
\hline $\begin{array}{l}\text { Repeatedly } \\
\text { disturbed rats }\end{array}$ & $\begin{array}{c}9: 9 \\
\text { (bowl) }\end{array}$ & $\begin{array}{l}15: 3 \\
\text { (cage) }\end{array}$ & $\begin{array}{c}6: 9 \\
\text { (bowl)* }\end{array}$ \\
\hline Significance $\$$ & ns & ns & $P<0.001$ \\
\hline
\end{tabular}

*Remained in the glass bowl for $45 \mathrm{~min}$.

$\uparrow$ Three animals which gave birth to Pup 8 within 30 min of Pup 3 are excluded from the analysis of birth distributions in the period $31-45 \mathrm{~min}$.

$¥$ The significance values are for a test of equality of proportions obtained by exact contingency table analysis.

\section{Plasma oxytocin concentrations during parturition}

After birth of Pups 2 and 3, oxytocin concentrations were $2 \mathrm{I} \cdot 4 \pm 2 \cdot 1$ ( $n=19$ rats) and $21 \cdot 3 \pm 1.5 \mathrm{pg} / \mathrm{ml}$ ( $n=63$ rats; both significantly higher than Day 22 pre-parturition samples; $P<0.001$ ). In all groups of saline-treated rats, whether disturbed or undisturbed, oxytocin concentrations rose progressively in the $40 \mathrm{~min}$ following the birth of the $3 \mathrm{rd}$ pup, but the increase was greater in the undisturbed rats (Fig. 3). Naloxone injection in disturbed and undisturbed rats resulted in a prompt and large rise in plasma oxytocin (Table 2) that was sustained for at least $40 \mathrm{~min}$. The mean plasma concentration $40 \mathrm{~min}$ after the birth of the Pup 3 was $48.2 \pm 8.0 \mathrm{pg} / \mathrm{ml}$ in 12 naloxone-treated disturbed rats; $72 \cdot 1 \pm 11.4 \mathrm{pg} / \mathrm{ml}$ in 10 naloxone-treated undisturbed rats; and $31 \cdot 8 \pm 2 \cdot 7 \mathrm{pg} / \mathrm{ml}$ in 10 control, undisturbed rats.

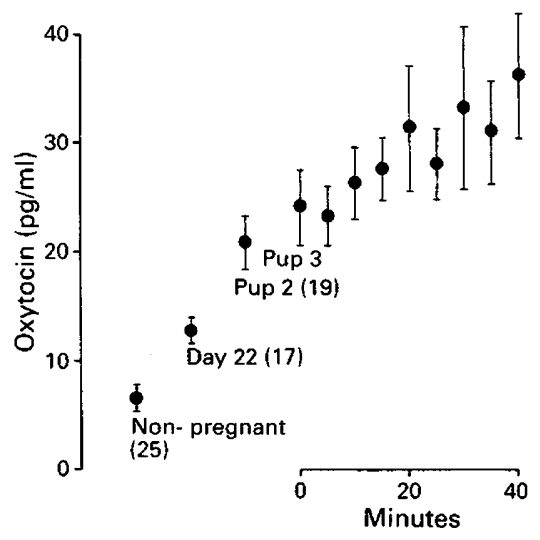

Fig. 3. Mean plasma oxytocin concentrations ( \pm s.e.) before and during parturition, measured by radioimmunoassay in jugular blood samples from conscious, chronically catheterized rats. The number of rats is given in parentheses for samples from non-pregnant rats, from rats on Day 22 of pregnancy before the onset of parturition, and from rats at the time of birth of Pup 2. The data shown for samples at and following the birth of Pup 3 all come from 11 rats; $n$ is between 7 and 11 for each of these points. 


\section{Effects of disturbance upon plasma oxytocin concentrations}

For each rat, we calculated the increment in plasma oxytocin $(\Delta)$ measured between the birth of Pup 3 and the mean oxytocin concentration measured in samples taken between 8 and 15 min later (Table 2). A model was fitted with expectations $E(\Delta)$ as given in Table 2 . Initially an unweighted fit was made, but as the variability of increments in the naloxone-treated animals was much greater than in the saline-treated animals it seemed more appropriate to use a weighted fit of the model giving greater weight to the less variable data (Table 3 ). Weighting inversely proportional to the variances suggested a relative weight for the data from saline-treated animals of about 25 as compared to 1 for the naloxone-treated animals. For a test that there was no influence of disturbance on plasma oxytocin concentration (i.e. that the true value of $\rho$, the proportionate influence of disturbance as defined in Table 2, is 1), the $t$ values were 6 and $4 \cdot 3$ for the two fits respectively on at worst 8 degrees of freedom. These results are significant at $P<0.001$ and $P<0.01$ for unweighted and weighted fits respectively. Therefore, considering the results as a whole, disturbance is associated with a significant depression of plasma oxytocin concentration.

Table 2. Parameters of the statistical model used to test the hypothesis that the influences of naloxone and of disturbance upon the progress of parturition in rats can be accounted for by their effects upon plasma oxytocin concentration

\begin{tabular}{llccccc}
\hline \multirow{2}{*}{ Treatment group } & & \multicolumn{2}{c}{ Plasma oxytocin increments } \\
\cline { 5 - 6 } Injection & Disturbance & & $\mathrm{E}(\Delta)^{*}$ & Mean $\Delta$ & s.e.m. & $\begin{array}{c}\text { No. of } \\
\text { rats }\end{array}$ \\
\cline { 5 - 6 } Saline & Undisturbed & & $\delta \mathrm{s}$ & 6.6 & 4.8 & 9 \\
Saline & Disturbed & & $\rho . \delta \mathrm{s}$ & 2.4 & 1.8 & 20 \\
Naloxone & Undisturbed & $\delta \mathrm{n}$ & 89.9 & 20.5 & 11 \\
Naloxone & Disturbed & & $\rho . \delta \mathrm{n}$ & 36.3 & 9.6 & 19 \\
\hline
\end{tabular}

*Measured between birth of Pup 3 and $8-15$ min later.

Table 3. Estimates of the parameters of the statistical model defined in Table 2 following an unweighted fit of the data, and a fit giving a weighting to the data from saline-treated animals which reffected the lower variance in these animals

\begin{tabular}{lcclcc}
\hline & \multicolumn{2}{c}{ Unweighted fit } & & \multicolumn{2}{c}{ Weighted fit } \\
\cline { 2 - 3 } \cline { 5 - 6 } $\mathrm{E}(\Delta)$ & Estimate & s.e. & & Estimate & s.e. \\
\hline$\delta \mathrm{s}$ & 6.4 & 10.9 & & 6.5 & 3.0 \\
$\delta \mathrm{n}$ & 89.9 & 11.4 & & $90 \cdot 1$ & $15 \cdot 4$ \\
$\rho$ & 0.40 & 0.11 & & 0.40 & 0.14 \\
\hline
\end{tabular}

\section{Relation between plasma oxytocin concentrations and birth intervals}

We analysed the relationship between the birth interval 3-4, and the mean oxytocin concentration $(\log )$ measured in samples taken between 8 and $15 \mathrm{~min}$ after the birth of Pup 3 . Fitting 
regression lines relating these two variables for each of the 6 experimental groups gave the regression coefficients shown in Table 4 . Within each group there was a downward trend, although this reached significance only for naloxone-treated disturbed rats. However, carrying out a pooled regression, allowing different intercepts for each group but a common slope, the regression is significant $(P<0.001)$ and the difference between the intercepts is not significant $(P>0.05)$. Therefore, although this analysis was only approximate, it indicated that the effects both of naloxone and of disturbance on the speed of parturition may be accounted for entirely by the relationship between the speed of parturition and the plasma oxytocin concentration.

Table 4. Regression of the interval between births of Pups 3 and 4 and the plasma oxytocin concentration $(\log )$ at $8-15$ min after birth of Pup 3

\begin{tabular}{|c|c|c|c|c|c|}
\hline \multicolumn{2}{|c|}{ Treatment group } & \multirow{2}{*}{$\begin{array}{l}\text { Constant } \\
\text { (s.e.) }\end{array}$} & \multirow{2}{*}{$\begin{array}{l}\text { Slope } \\
\text { (s.e.) }\end{array}$} & \multirow[b]{2}{*}{$t$} & \multirow{2}{*}{$\begin{array}{l}\text { No. of } \\
\text { rats }\end{array}$} \\
\hline Injection & Disturbance & & & & \\
\hline Naloxone & Undisturbed & $24 \cdot 4(10 \cdot 1)$ & $-8.99(4.99)$ & -1.80 & 10 \\
\hline Naloxone & Disturbed & $54.5(13 \cdot 3)$ & $-24 \cdot 40(7 \cdot 52)$ & $-3 \cdot 35$ & 11 \\
\hline Naloxone & Repeatedly disturbed & $27 \cdot 1(15 \cdot 8)$ & $-11 \cdot 18(9 \cdot 25)$ & $-1 \cdot 21$ & 5 \\
\hline Saline & Undisturbed & $42 \cdot 4(15 \cdot 3)$ & $-23 \cdot 4(10 \cdot 7)$ & $-2 \cdot 17$ & 8 \\
\hline Saline & Disturbed & $28 \cdot 9(14 \cdot 0)$ & $-6 \cdot 1 \quad(11 \cdot 1)$ & -0.55 & 12 \\
\hline Saline & Repeatedly disturbed & $62 \cdot 3(18 \cdot 2)$ & $-33.8 \quad(13.8)$ & -2.44 & 5 \\
\hline
\end{tabular}

Pooling all groups, the regression is highly significant $(P<0 \cdot 001)$.

Looking more closely for evidence of independent effects of disturbance and of naloxone upon the progress of parturition we broke the treatment term into a $2 \times 2$ factorial (combining data from disturbed and repeatedly disturbed groups since there was no difference between the treatment of these groups in the relevant time period). We obtained a significant difference in the intercepts of the regression lines fitted to disturbed and undisturbed animals $(P<0.05)$. The improvement in the model achieved by allowing different slopes and intercepts for these two groups is significant $(P<0.05 ; \mathrm{F}$ on 2 and $59 \mathrm{~d} . \mathrm{f}$. $=3.79)$. Therefore, while there is virtually no effect of naloxone on the relationship between speed of parturition and plasma oxytocin concentration, the disturbed animals may have a larger intercept and a steeper slope for the regression of speed of parturition against plasma oxytocin concentration (Fig. 4).

\section{Effects of naloxone on plasma oxytocin concentration before and after parturition}

Plasma oxytocin concentrations in non-pregnant rats were $6.8 \pm 1 \cdot 1 \mathrm{pg} / \mathrm{ml}(n=25)$, and did not change significantly following injection of naloxone or saline (Fig. 5). On Day 22 of pregnancy, oxytocin concentrations in rats before the onset of parturition were $13 \cdot 1 \pm 1 \cdot 3 \mathrm{pg} / \mathrm{ml}(n=17)$, significantly higher than in non-pregnant rats $(P<0.01 ;$ Fig. 3$)$, and in these rats oxytocin concentrations were not significantly affected by saline injection but were significantly elevated after naloxone (Fig. 5). On the day after parturition plasma oxytocin concentrations averaged $11.7 \pm 1.7 \mathrm{pg} / \mathrm{ml}(n=19$; significantly higher than in non-pregnant rats). Oxytocin concentrations in these rats were unaffected by saline or naloxone injection (Fig. 5). We therefore found evidence for endogenous opioid inhibition of oxytocin release on Day 22 of pregnancy but not in nonpregnant rats or in rats on Day 1 post partum. The rise following naloxone in parturient rats was significantly greater than in Day 22 pre-parturition samples $(P<0.01)$, hence endogenous opioid inhibition of oxytocin release appeared to be greatest during parturition itself. 


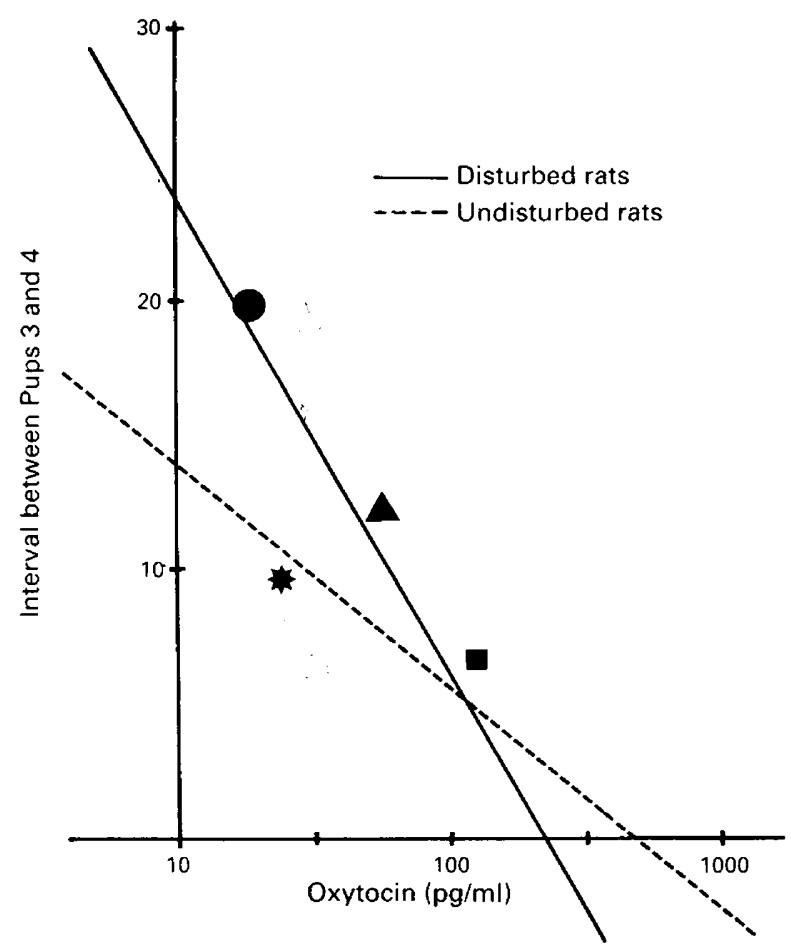

Fig. 4. Effects of naloxone and of disturbance during labour on plasma oxytocin concentrations, measured by radioimmunoassay from jugular blood samples. Rats were removed from their nesting cage into a glass chamber following the birth of Pup 3 (disturbed rats), and at this time were given an i.v. injection of naloxone hydrochloride $(2 \mathrm{mg} / \mathrm{kg}$ body wt $)$ or $0.9 \%$ saline. The lines shown are regressions of the interval between the births of Pups 3 and 4 , and the mean log plasma oxytocin concentration measured between 8 and $15 \mathrm{~min}$ after the birth of Pup 3. The group means are shown for naloxone-treated disturbed rats $(\boldsymbol{\Delta})$; naloxone-treated undisturbed rats $(\boldsymbol{\square})$; saline-treated disturbed rats $(\boldsymbol{\bullet})$, and saline-treated undisturbed rats $\left(^{*}\right)$.

\section{Neurointermediate lobe content of oxytocin}

The neurointermediate lobe content of oxytocin was elevated on Day 22 of pregnancy in glands removed before the onset of parturition $(3.64 \pm 0.13 \mu \mathrm{g} / \mathrm{gland}, n=9$, vs $2.79 \pm 0.12 \mu \mathrm{g} / \mathrm{gland}$, $n=11$, non-pregnant rats). Content was significantly lower in glands removed $45 \mathrm{~min}$ after the birth of Pup 3, but no differences were found between disturbed and undisturbed rats or between naloxone-treated and saline-treated rats $(2.83 \pm 0.13 \mu \mathrm{g} / \mathrm{gland}(n=7)$ in undisturbed, control rats; $2.55 \pm 0.14 \mu \mathrm{g} / \mathrm{gland}(n=12)$ in repeatedly disturbed, saline-treated rats; $2.55 \pm 0 \cdot 11 \mu \mathrm{g} / \mathrm{gland}$ $(n=11)$ in repeatedly disturbed, naloxone-treated rats; no significant differences between these groups; value for each group significantly lower than that for glands removed before the onset of parturition).

\section{Discussion}

The present results confirm that environmental disturbance prolongs parturition, as first shown in the mouse (Newton et al., 1966, 1968). Notwithstanding large variability between animals, the results also provide clear evidence both that the interval between deliveries is related to plasma oxytocin concentration, and that the effects of disturbance upon the speed of parturition may, at 


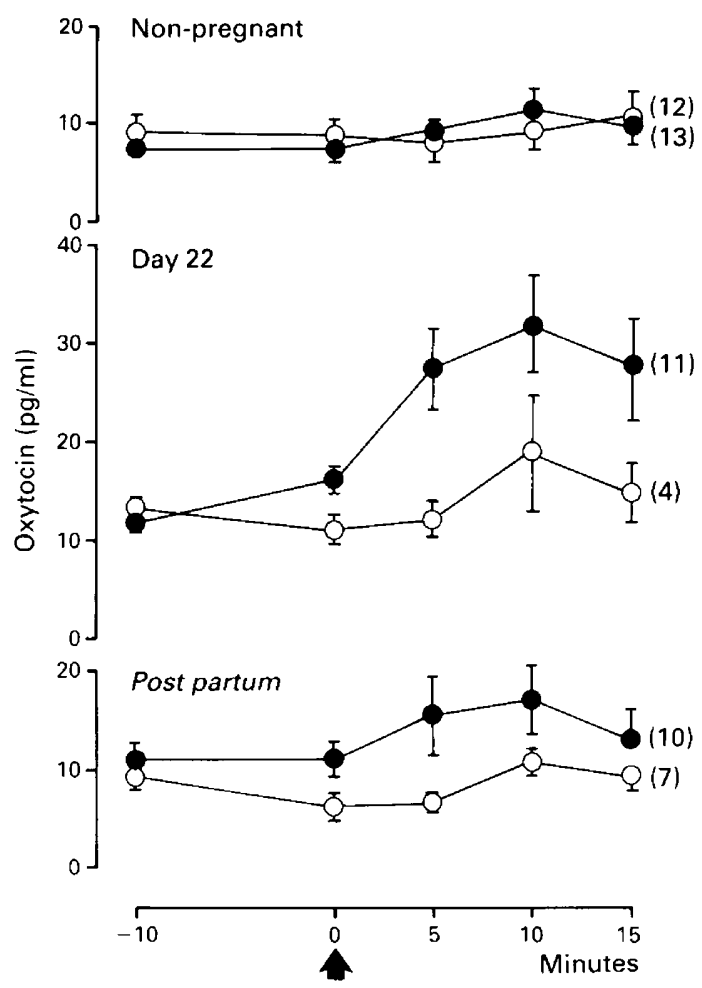

Fig. 5. Effects of injection of naloxone hydrochloride (i.v.; $2 \mathrm{mg} / \mathrm{kg}$ body wt; closed symbols) or $0.9 \%$ saline (open symbols) on plasma oxytocin concentrations, measured by radioimmunoassay from jugular blood samples in conscious rats. Injections of saline or naloxone were given immediately after the second sample (arrow). Values are mean \pm s.e.m. for the number of rats given in parentheses.

least in part, be accounted for by depression of plasma oxytocin concentrations. As in a previous study (Leng et al., 1987), naloxone administration prevented the disruption of parturition, apparently by elevating oxytocin concentrations in the circulation. In our previous studies, rats were anaesthetized with tribromoethanol for cannulation, and such anaesthesia late in pregnancy significantly delays the onset of parturition. This was not true of the present study in which ether anaesthesia was used: all rats gave birth, as expected, on Day 22 or Day 23 of pregnancy. The effects of disturbance, and their reversibility by naloxone, are therefore not features only of retarded parturition (Leng et al., 1987).

Our results differed in one important respect from those previously obtained using tribromoethanol anaesthesia: naloxone markedly hastened parturition in undisturbed animals in the present, but not in the previous, study. Therefore, comparing disturbed and undisturbed animals, it is clear that naloxone does not eliminate the effects of disturbance. The difference between the two studies may therefore reflect additional stress in the tribromoethanol-treated animals associated with the retardation of the onset of parturition, although within each study we found no correlation between the time of onset of parturition and the duration of parturition.

The present study demonstrated that naloxone elevates oxytocin secretion in disturbed and undisturbed parturient rats. Electrophysiological recordings from oxytocin cells during parturition in conscious rats suggest that, on top of an elevated background release, oxytocin is also released in pulses, and that the occurrence of pulses is correlated with the births of individual pups (Summerlee, 1981). The half-life of oxytocin in rat plasma is about $1.5 \mathrm{~min}$ (Higuchi et al., 1985), 
but the disappearance time of a bolus of oxytocin introduced into the circulation by a brief, synchronized burst of activity from oxytocin cells is likely to be much less, since the disappearance rate will be dominated by the speed of dilution of the bolus into the whole volume of circulating blood. An analogous pulsatile release of oxytocin occurs during suckling in lactating rats, and to detect such release by RIA requires very frequent blood sampling (Higuchi et al., 1985, 1986). In the present experiments samples were taken at 5- or 10-min intervals, and plasma concentrations tended to be consistent within animals (disregarding the effects of naloxone). Thus our sampling provided no direct information on the rate or amplitude of pulsatile hormone release, and this qualification requires us to be circumspect about some conclusions.

The relationship of oxytocin concentration to inter-birth interval is not simple. In control rats, the intervals between births were fairly constant between the birth of Pups 2 and 7, although oxytocin concentrations rose progressively over this period. Naloxone injections produced a prolonged elevation of plasma oxytocin, but only a transient effect on the speed of parturition. The naloxone-treated disturbed rats had higher plasma oxytocin concentrations than did the salinetreated undisturbed rats, but the progress of parturition was very similar in these two groups. Nevertheless, within each experiment group there was a positive correlation between plasma oxytocin concentration and the speed of parturition, and overall this correlation was highly significant. It is likely that during parturition oxytocin is released in pulses superimposed upon an elevated background secretion, and that a pulse of oxytocin triggers the delivery of each pup (Summerlee, 1981). The background secretion of oxytocin, measured in the present experiments, may contribute to the sensitivity of the uterus to pulses of oxytocin but probably does not fully determine the timing of births.

From our data as a whole, disturbance in mid-parturition was accompanied by depressed secretion of oxytocin. Naloxone resulted in a marked potentiation of oxytocin release during parturition, and it seems that this potentiated release was sufficient to overcome the disruption of parturition caused by environmental disturbance. Since naloxone increased the speed of parturition in undisturbed rats also, the simplest explanation is that environmental disturbance slows parturition by suppressing oxytocin release, possibly by mechanisms independent of endogenous opioid pathways, and that naloxone speeds parturition by elevating oxytocin secretion but similarly acts independently of whether the animal has been disturbed. Thus the data support our original hypothesis that endogenous opioids regulate oxytocin release during normal parturition, and may be involved in 'spacing' the deliveries of successive pups (Leng et al., 1985).

Another role for opioid pathways may be in determining the onset of parturition. Jones \& Summerlee $(1986 a, b)$ have suggested that secretion of the ovarian hormone relaxin is involved in the co-ordination of central and peripheral events necessary for parturition to proceed, and that one role of relaxin in the period before the onset of parturition is to inhibit oxytocin release via the activation of brain opioid pathways. In late pregnancy, the concentration of relaxin in the maternal circulation of the rat is high and falls precipitously shortly before the onset of parturition (Sherwood et al., 1980). Recent evidence suggests that the elevated relaxin concentrations of late pregnancy inhibit oxytocin secretion via opioid pathways (Summerlee et al., 1984; O’Byrne \& Summerlee, 1985; O'Byrne et al., 1986). Chronic infusions of exogenous relaxin delay the onset of parturition and suppress oxytocin release during parturition (Jones \& Summerlee, 1986a, b), and these effects of relaxin are reversed by naloxone.

Inhibition of oxytocin release by relaxin would conserve neurohypophysial oxytocin stores for parturition, might result in a further sensitization of the uterus already sensitized by the proliferation of oxytocin receptors (Fuchs \& Poblete, 1970), and would prevent premature uterine activation by oxytocin until the relaxin-induced softening of the cervix was complete (Harkness \& Harkness, 1959). Withdrawal from prolonged exposure to opioids results in hypersecretion of oxytocin (Bicknell et al., 1988), and the rapidly falling plasma concentration of relaxin on Day 22 of pregnancy (Sherwood et al., 1980) may similarly provoke an opioid-withdrawal hypersecretion of oxytocin to initiate or help maintain parturition. 
This hypothesis is supported by some of our data. We demonstrated that there is tonic opioid inhibition of oxytocin release on Day 22 of pregnancy before the onset of parturition, whereas little opioid influence was discernible in non-pregnant rats or on Day 1 post partum. On the other hand, naloxone effects on oxytocin release were greater during parturition, whereas it might be expected that, if opioid withdrawal was already underway, then naloxone should be less effective at this time. However, oxytocin release is not linearly related to the discharge rate of oxytocin neurones: there is a marked frequency-facilitation of oxytocin release, which means that a given increase in firing rate will produce a larger oxytocin release if the basal concentration of firing is high (Leng \& Bicknell, 1984). The high concentrations of oxytocin release sustained throughout parturition suggest that oxytocin cells indeed have a high degree of basal activity throughout parturition (see Summerlee, 1981).

Which opioid system is involved in oxytocin regulation during parturition remains uncertain. Oxytocin release is under inhibitory opioid control at the level of the neurohypophysis, probably by dynorphin co-released with vasopressin (Bicknell et al., 1985; Summy-Long et al., 1986; Zhao et al., 1988). If this opioid system is active during parturition, then elevated vasopressin concentrations might also be found. Vasopressin release is elevated throughout pregnancy in the rat (Lindheimer et al., 1985). However, in both rabbits (Haldar, 1970) and rats (Hartman et al., 1986) little vasopressin is released during parturition as compared with oxytocin.

Oxytocin secretion is also under opioid control at the concentration of the neurosecretory cell bodies (Bicknell et al., 1988), which appear to be innervated by a $\beta$-endorphinergic projection from the hypothalamic arcuate nucleus (Sawchenko et al., 1982). Brain $\beta$-endorphin concentrations are elevated throughout pregnancy in the rat (Wardlaw \& Frantz, 1983), and remain elevated until 1-2 days post partum. Relaxin administration depresses the electrical activity of oxytocin neurones (Summerlee et al., 1984), hence the endogenous opioid control of oxytocin release during parturition is likely to be exerted, at least in part, centrally rather than at the neurohypophysis.

We thank Dr T. Higuchi for the generous gift of oxytocin antiserum. K.S. was supported by The British Council; R.E.B. is an A.F.R.C. scholar, and S.H. is an M.R.C. scholar.

\section{References}

Bicknell, R.J., Chapman, C. \& Leng, G. (1985) Effects of opioid agonists and antagonists on oxytocin and vasopressin release. Neuroendocrinology 41, 142-148.

Bicknell, R.J., Leng, G., Lincoln, D.W. \& Russell, J.A. (1988) Naloxone excites oxytocin neurones in the supraoptic nucleus of lactating rats after chronic morphine treatment. J. Physiol., Lond. 396, 297-317.

Cutting, R., Fitzsimons, N., Gosden, R.G., Humphreys, E.M., Russell, J.A., Scott, S. \& Stirland, J.A. (1986) Evidence that morphine interrupts parturition in rats by inhibiting oxytocin secretion. J. Physiol., Lond. 371, 182P, Abstr.

Dyer, R.G. (1988) Oxytocin and parturition-new complications. J. Endocr. 116, 167-168.

Fuchs, A.-R. \& Poblete, V.F. (1970) Oxytocin and uterine function in pregnant and parturient rats. Biol. Reprod. 1, 344-353.

Gosden, R.G., Humphreys, E.M., Johnston, V., Liddle, S. \& Russell, J.A. (1985) Morphine acts centrally to interrupt established parturition in the rat. $J$. Physiol., Lond. 364, 59P, Abstr.

Haldar, J. (1970) Independent release of oxytocin and vasopressin during parturition in the rabbit. $J$. Physiol., Lond. 206, 723-730.

Harkness, M.L.R. \& Harkness, R.D. (1959) Changes in the properties of the uterine cervix of the rat during pregnancy. J. Physiol., Lond. 148, 524-547.

Hartman, R.D., Rosella-Dampman, L.M., Emmert, S.E. \& Summy-Long, J.Y. (1986) Inhibition of neurohypophysial hormones by endogenous opioid peptides in pregnant and parturient rats. Brain Res. 382, 352-359.

Higuchi, T., Honda, K., Fukuoka, T., Negoro, H. \& Wakabayashi, K. (1985) Release of oxytocin during suckling and parturition in the rat. J. Endocr. 105, 339-346.

Higuchi, T., Tadokoro, Y., Honda, K. \& Negoro, H. (1986) Detailed analysis of blood oxytocin concentrations during suckling and parturition in the rat. $J$. Endocr. 110, 251-256.

Higuchi, T., Uchide, K., Honda, K. \& Negoro, H. (1987) Pelvic neurectomy abolishes the fetus-expulsion reflex and induces dystocia in the rat. Exp. Neurol. 96, 443-455.

Jones, S.A. \& Summerlee, A.J.S. (1986a) Effects of porcine relaxin on the length of gestation and parturition in the rat. $J$. Endocr. 109, 85-88.

Jones, S.A. \& Summerlee, A.J.S. (1986b) Relaxin acts centrally to inhibit oxytocin release during parturition: an effect that is reversed by naloxone. J. Endocr. 111, 99-102. 
Leng, G. \& Bicknell, R.J. (1984) Patterns of electrical activity and hormone release from neurosecretory cells. In Endocrinology, pp. 1020-1023. Eds F. Labrie \& L. Proulx. Elsevier, North Holland.

Leng, G., Mansfield, S., Bicknell, R.J., Dean, A.D.P., Ingram, C.D., Marsh, M.I.C., Yates, J.O. \& Dyer, R.G. (1985) Central opioids: a possible role in parturition? J. Endocr. 106, 219-224.

Leng, G., Mansfield, S., Bicknell, R.J., Brown D., Chapman, C., Hollingsworth, S., Ingram, C.D., Marsh, M.I.C., Yates, J.O. \& Dyer, R.G. (1987) Stress-induced disruption of parturition in the rat may be mediated by endogenous opioids. J. Endocr. 114, 247-252.

Lindheimer, M.D., Barron, W.M. \& Davison, J.M. (1985) Water metabolism and vasopressin secretion in pregnancy. In Vasopressin, pp. 229-240. Ed. R. W. Schrier. Raven Press, New York.

Newton, N., Foshee, D. \& Newton, M. (1966) Parturient mice: effect of environment on labor. Science, N.Y. 151, 1560-1561.

Newton, N., Peeler, D. \& Newton, M. (1968) Effect of disturbance on labor. Am. J. Obstet. Gynec. 101, 1096-1102.

O'Byrne, K.T. \& Summerlee, A.J.S. (1985) Naloxone reverses relaxin inhibition of oxytocin release in the rat. Neurosci. Lett. 22, S573, Abstr.

O'Byrne, K.T., Eltringham, L., Clarke, G. \& Summerlee, A.J.S. (1986) Effects of porcine relaxin on oxytocin release from the neurohypophysis in the anaesthetized lactating rat. J. Endocr. 109, 393-397.
Sawchenko, P.E., Swanson, L.W. \& Joseph, S.A. (1982) The distribution and cells of origin of ACTH(1-39)stained varicosities in the paraventricular and supraoptic nuclei. Brain Res. 232, 365-374.

Sherwood, O.D., Crnekovic, V.E., Gordon, E.L. \& Rutherford, J.E. (1980) Radioimmunoassay of relaxin throughout pregnancy and parturition in the rat. Endocrinology 107, 691-698.

Summerlee, A.J.S. (1981) Extracellular recordings from oxytocin neurones during the expulsive phase of birth in unanaesthetised rats. J. Physiol., Lond. 321, 1-10.

Summerlee, A.J.S., O'Byrne, K.T., Paisley, A.C., Breeze, M.F. \& Porter, D.G. (1984) Relaxin affects the central control of oxytocin release. Nature, Lond. 309, $372-374$.

Summy-Long, J.Y., Denlinger, C., Palm, D., Hartman, R.D. \& Rosella-Dampman, L.M. (1986) Naloxone effects on plasma vasopressin and oxytocin concentrations elevated by histamine, nicotine, isoproterenol and an acute increase in $[\mathrm{NaCl}]$ in cerebrospinal fluid. Neuroendocrinology 44, 157-162.

Wardlaw, S.L. \& Frantz, A.G. (1983) Brain $\boldsymbol{\beta}$-endorphin during pregnancy, parturition, and the postpartum period. Endocrinology 113, 1664-1668.

Zhao, B., Chapman, C. \& Bicknell, R.J. (1988) Opioidnoradrenergic interactions in the neurohypophysis. Neuroendocrinology (in press).

Received 19 February 1988 